\title{
OS LIMITES DO REALISMO EM THE MUTILATED, DE TENNESSEE WILLIAMS: EXPRESSIONISMO E VERFREMDUNGSEFFEKT
}

Gustavo Ponciano Cunha de Oliveira* Universidade Federal de Goiás Goiânia, Goiás, BR

\section{Resumo}

Este artigo inicia sua reflexão sobre a dificuldade de parcela da crítica em classificar a produção dramática de Tennessee Williams (1911-1983) sob termos rígidos, especialmente ao tentar vinculá-lo ao “Realismo". Porém, a atenção às notas de produção de The Glass Menagerie (1944) - o manifesto do que o dramaturgo chama de Plastic Theatre - evidencia que o desejo do autor era o de afastar-se das convenções dramáticas do Realismo descritivo. Ao final, o estudo localiza em The Mutilated (1967), de Williams, o influxo de características caras ao Expressionismo e ao Verfremdungseffekt brechtiano, técnicas dramáticas que apontam para outra concepção de Realismo. Palavras-chave: Tennessee Williams; Realismo; Plastic Theatre; Expressionismo; Verfremdungseffekt

\section{THE LIMITS OF REALISM IN THE MUTILATED, BY TENNESSEE WILLIAMS: EXPRESSIONISM AND VERFREMDUNGSEFFEKT}

\begin{abstract}
This paper starts the research reading the hesitations of literary and theatrical criticism in its proposition to classify Tennessee Williams's (1911-1983) dramatic writing, especially the critics who try to restrict the playwright's works under the term "Realism". Adverse to this criticism, the production notes from The Glass Menagerie (1944) -Williams's Plastic Theatre manifesto - reveal the author's intentions to get rid of orthodox Realism theatre conventions in his plays. Finally, the study points in Williams's The Mutilated (1967) some remarkable qualities -expressionist techniques and uses of brechtian Verfremdungseffekt - that allude to a distinct conception of Realism. Keywords: Tennessee Williams; Realism; Plastic Theatre; Expressionism; Verfremdungseffekt
\end{abstract}

A hesitação dos especialistas ao classificar a produção dramática do estadunidense Tennessee Williams (1911-1983) parece ser uma constante. Tão comum quanto a atribuição de qualidades realistas ao autor é a marcação de um desvio de Williams em relação aos protocolos do Realismo; por vezes, os comentários, como os de J. L. Styan (2003, p. 1), avançam a um próximo estágio ao destacar o caráter escorregadio do epíteto realista. "It is axiomatic that each generation feels that its theatre is in some way more 'real' than the last"'.
O paradigma ao qual Styan dedica-se em sua análise é o do drama como descrição, que se opõe ao drama apreendido em termos apenas narrativos. Como anota David Lescot (2012, p. 155), o drama como descrição, proposto pelo tableau de Denis Diderot, funciona como uma focalização sobre uma fração do mundo, recorte similar ao da moldura em um quadro, "que se impõe ao espectador como uma presença visual e silenciosa" (LOSCO, 2012, p. 176). Mesmo que ao fim Styan afirme que, na prática, no palco, o resultado alcançado no

* Doutorando e mestre em Estudos Literários pelo programa de Pós-graduação em Letras e Linguística da Universidade Federal de Goiás. Foi professor substituto de Teoria e Ensino de Literatura da Faculdade de Letras da UFG. Seus principais interesses de pesquisa são teoria e crítica literárias, teoria da narrativa, literatura e cinema, literatura e filosofia e, seu objeto de pesquisa no curso de doutoramento, a obra de Jorge Luis Borges. Seu endereço de email é gponciano.co@gmail.com 
embate que as gerações dramáticas travam com as suas antecessoras não seja mais que uma nova convenção, o pesquisador concentra-se na ideia de Realismo como movimento ou escola no qual o referente pretendido é o real, aquele que Lescot (2012, p. 156) exemplifica com Gerhart Hauptmann, cujo sonho, em Os tecelões, "seria menos narrar a ação dos operários de Peterswaldau do que representar seu meio e as condições objetivas de sua existência, projeto que traduziríamos de bom grado em termos não dramáticos como descrição ou hipotipose"; e ainda com a notória proposta de André Antoine, de que encenação moderna no teatro deveria alcançar a mesma função que a descrição desempenha no romance.

A pequena coleção de hesitações críticas que virá a seguir está calcada nesta ideia de Realismo hipotipótico ou descritivo, à qual, tão logo enumerados seus exemplos, contraporemos outra apreensão de Realismo: aquele que, por meio de uma forma experimental ou artificial, investiga o subterrâneo da realidade. Nosso intuito, além de apresentar esta concepção não ortodoxa de Realismo, que associaremos a Tennessee Williams, é demonstrar que a hesitação crítica pode alcançar uma reação de indisposição diante do referido dramaturgo, fundada na leitura equivocada de sua obra, especialmente na não aceitação de sua estrutura experimental.

Signi Falk (1966, p. 21) defende a tese de que Williams integra a Renascença Sulista: "o aparecimento durante as décadas do meio do século vinte de uma literatura rica e variada sobre o Sul [dos Estados Unidos]". Nos interessam aqui os indícios de que o citado movimento, ao qual Williams é conectado, surge sob atributos constantemente associados ao Realismo descritivo, como revela a enunciação da pesquisadora sobre suas origens: "Uma espécie de lealdade regional para com a tradição, uma nostalgia para um modelo de aristocracia, uma vida não-urbana que foi rica em promessas, uma consciência de personalidades distintas, costumes e crenças próprias da região sulista”. Ao enumerar autores que enquadra sob a denominação e exemplificando a temática do grupo, Falk (1966, p. 22-24) continua a citar ideias associadas a paradigmas "realistas", como o registro de "sua própria vida", a "observação direta da vida e das pessoas", dedicação "ao indivíduo num ambiente hostil" e "aos problemas sociais de sua região". Ao tratar da coletânea Twenty-seven Wagons Full of Cotton and Other One-Act Plays (1945), Falk (1966, p. 46) afirma que Williams opera "num estilo realista", gerando simpatia pela delinquência, pelo delito e pelo não convencional.

Styan (2003, p. 137) concede o $15^{\circ}$ capítulo de Modern Drama in Theory and Practice: Realism and $\mathrm{Na}$ turalism, intitulado "Realism in America", a dois dramaturgos estadunidenses, "both writing essentially in the realistic mode": Tennessee Williams e Arthur Miller. Styan compara os dois, respectivamente, a Anton Tchekhov e Henrik Ibsen, nomes usualmente referenciados no debate sobre o Realismo no teatro, mas que também recebem a marca do desvio: Szondi (2001, p. 35-53) aponta ambos como confrontadores, autores que põem em crise o drama tradicional, respectivamente, pela renúncia ao presente e pela técnica analítica.

Porém, mesmo ao enquadrar Williams na Renascença Sulista, Falk (1966, p. 27) afirma que suas últimas produções "parecem ser um excelente material para alguma biografia futura", referindo-se a uma incorporação do autor ao texto, uma das características apontadas por Szondi (2001, p. 59) como as do dramaturgo da subjetividade. Falk (1966, p. 26) declara ainda que o trabalho de Williams, como o de Faulkner, "compreende desde o realismo até um simbolismo envolvido". Já Styan, ao tratar de The Glass Menagerie (1944), cita os cenários não-realistas, o caráter épico e memorialista da peça e compara os mecanismos desenvolvidos por Piscator para projeção de imagens e legendas em cena àqueles sugeridos por Williams (2000a, p. 394-465) em suas notas de produção.

A mesma oscilação ocorre, com singular sutileza, no comentário de Margot Berthold (2011, p. 519) a The Glass Menagerie (1944), peça que, afirma, contém o tema ao qual o dramaturgo aplica um processo de variação, cada vez mais grotesco, ao longo de sua produção: "Williams autobiograficamente refletiu sobre as lastimáveis pretensões dos remanescentes da tradição sulista e mostrou sensibilidade refugiando-se da aspereza do mundo moderno nos sonhos e no retraimento". A primeira metade da citação, a da representação do 
suposto direito reivindicado por uma camada da sociedade estadunidense, demarcada espacialmente, remete a argumentos comumente associados à representação realista em sua acepção descritiva; a segunda, sobre a "sensibilidade", junto ao comentário sobre o caráter autobiográfico, os inquieta.

Sábato Magaldi, ao também comentar The Glass Menagerie, expressa com sagacidade como é árduo o exercício da crítica que se propõe a categorizar o teatro de Williams, mas não sem o juízo de valor negativo e a remissão de seu interesse ao exercício descritivo da realidade:

Assim como todo bom teatro, de Ésquilo a Brecht, a peça se inclui na categoria do realismo poético, expressão por certo híbrida, e que parece emprestada à inconsistência eclética, mas é a única a englobar os requisitos de tratamento artístico de uma realidade que, de outra forma, se contentaria com o estilo da reportagem. (MAGALDI, 2012, p. 353)

Em artigo de sugestivo título, "Camino Unreal", Eric Bentley analisa uma montagem da peça Camino Real (1946) produzida por Elia Kazan. Ao manifestar seu descontentamento com o texto de Williams, inicia análise que revela a dificuldade em classificar o dramaturgo sob conceitos inflexíveis:

The script, when I read it some time ago, I disliked - partly because it belongs to the current deliquescent-rococo type of theatre and even more because it seemed far from a brilliant example of the type. The genuine element in Tennessee Williams had always seemed to me to reside in his realism: his ability to make eloquent and expressive dialogue out of the real speech of men and his gift for portraiture, especially the portraiture of unhappy women. There is also a spurious element. Sometimes it's his style that is spurious, for when he is poetic he is often luscious and highfalutin'. (BENTLEY, 1954, p. 107)

Para Bentley, Camino Real é o ápice do espúrio na produção dramática de Williams. ${ }^{4}$ Ao compará-la com A Streetcar Named Desire (1947), Bentley (1954, p. 110) destaca no teatro do autor (especialmente nas encenações de Kazan) a aura fantasmagórica. "Blanche Dubois' background was diaphanous walls and voices disembodied as Saint Joan's. [...] The only difference is that Camino Real doesn't even pretend to realism. The unreal which formerly crept up on us here meets us head on". Exemplo do que Bentley afirma pode ser encontrado na cena 10 da peça, na qual Blanche é atacada pelo cunhado, Stanley. A situação de descontrole interno da protagonista invade o espaço por meio da iluminação e da sonorização. As paredes tornam-se transparentes para dar à visão uma briga entre uma prostituta e um bêbado no meio da rua, paralelo do que está por acontecer na residência, entre os cunhados. As vozes dos transeuntes tornam-se grunhidos animalescos; as notas do "piano azul", em crescendo, convertem-se no ruído opressivo de uma locomotiva se aproximando (WILLIAMS, 2000c, p. 542-555). Porém, mais uma vez, o paradigma sob o qual Williams é julgado é o do Realismo descritivo, mesmo que, no ápice de sua flexibilização (que coincide com o único juízo positivo), seja apreendido como convenção: o retrato de recorrentes mulheres infelizes e os diálogos incapazes de reproduzir o discurso dos homens da realidade.

Felicia Londré (1979, p. 162), ao comentar The Mutilated, o texto de Williams ao qual nos dedicaremos com mais atenção, alcança o ápice da negatividade contida na hesitação da crítica que se conduz a partir da ideia de Realismo descritivo. Afirma a pesquisadora: "Williams's compassion for human outcasts is as sincere as ever in The Mutilated, but the play itself is too loosely constructed to win the traditional kind of audience involvement. At the same time, paradoxically, it is not experimental enough". Na leitura crítica, o tradicional paradigma de Realismo concentra-se no destaque à eficácia de Williams em registrar párias; seu contraponto é formal - a incapacidade deste comovente retrato adaptar-se à construção "frouxa" do drama. Parece, inicialmente, haver na afirmação da pesquisadora a exigência de que o dramaturgo opte por um dos polos por ela apresentados (tradicional $v s$. experimental). Mas, se nos atemos à avaliação negativa, a paradoxal insuficiência experimental concomitante à falta de rigor da composição que não atrai o público tradicional, verificamos que, no enunciado 
crítico, habita mais profundamente a exigência de uma injustiça maior do que a polarização de aspiração maniqueísta: a exigência de que Williams retome uma concepção de Realismo que, de fato, não defendeu.

A partir das leituras realizadas, a avaliação é a de que a crítica oscila em suas análises por responder (cientemente ou não) a um desejo de liberdade formal que Williams aplica, em variadas gradações, aos seus textos dramáticos, especialmente a partir de The Glass Menagerie, mas que já se manifesta com intensidade em The Long Goodbye (1940), peça de um ato que integra a coletânea Twenty-seven Wagons Full of Cotton. Neste drama, a análise da relação familiar (à qual se apegaria a crítica que insiste em classificar Williams como "realista”, mas ilegítimo, por não aceitar suas preferências formais), seu caráter memorialista, os espectros do passado que invadem a cena e o uso da iluminação e da sonorização para a construção da ambiência fantasmagórica (WILLIAMS, 1966, p. 161-179) são prenúncio do que surgiria no drama sobre a família Wingfield.

As notas de produção de The Glass Menagerie funcionam como o manifesto do que Williams chama de Plastic Theatre, expressão cunhada pelo dramaturgo para nomear seu ideal de drama, livre de convenções. $\mathrm{O}$ autor deixa claro que suas ideias apresentadas no texto introdutório não cabem exclusivamente à peça anotada, mas à proposta de ocupar o lugar do desgastado teatro das convenções realistas, comparado por ele à fotografia, que apresenta (apenas) a aparência de seus objetos. A ideia de que as personagens devem falar como a audiência que as ouve, que a geladeira e os cubos de gelo em cena serão sempre genuínos, é território do convencional e da crítica afastada da prática do teatro, defende Williams (2000a, p. 395). Pela imaginação poética, afirma o dramaturgo, este mesmo material é representado ou sugerido por meio da transformação.

Lescot (2012, p. 156) chega a uma compreensão do Realismo próxima à proposta de Williams ao acionar Kafka, pró e contra, de Günther Anders; destaca que, "mais uma vez, o desvio pela narrativa, pelo romance, ilumina o teatro". Em seu texto, Anders (2007, p. 1516) anota que já deveríamos estar familiarizados com o método de Franz Kafka, a deformação. Consiste em uma conformação prévia na qual o objeto é posterior- mente inserido para que seja revirado, invertido. É por meio deste procedimento experimental que o "fabulador realista” (p. 16), Franz Kafka, “deslouca a aparência aparentemente normal de nosso mundo louco, para torná-la visível"' (p. 15). Nessa esteira, prossegue Lescot (2012, p. 156), o Realismo não é a representação que deseja "copiar o real, mas expor suas engrenagens". A este Realismo filia-se Brecht, um inventor de fábulas, repete Lescot (p. 157) a proposta já feita por Anders (p. 16). Nosso intento é, por meio da análise dos procedimentos formais e das propostas estéticas, agregar Tennessee Williams a essa categoria de Realismo.

Ao apresentar o Plastic Theatre, Williams revela uma das fontes de técnicas dramáticas não convencionais das quais se vale, o Expressionismo, e explica qual é seu interesse ao aplicá-las:

Expressionism and all other unconventional techniques in drama have only one valid aim, and that is a closer approach to truth. When a play employs unconventional techniques, it is not, or certainly shouldn't be, trying to escape its responsibility of dealing with reality, or interpreting experience, but is actually or should be attempting to find a closer approach, a more penetrating and vivid expression of things as they are. (WILLIAMS, 2000a, p. 395) $^{8}$

O polo experimental na hesitação crítica, que parece conduzir os mais inflexíveis à indisposição tão logo seja feito o contato com a obra de Williams, é, na conjectura do próprio autor, o ponto de partida rumo ao êxito do acesso dramático "às coisas como elas são". Onde a crítica mais ortodoxa vê incompatibilidade (especialmente da forma), Williams vê responsabilidade autoral frente à representação.

Como comentam Greta Heintzelman e Alycia Smith-Howard (2005, p. 92), as notas de produção de The Glass Menagerie contrariaram, como era de se esperar, a parcela da crítica associada às tradições do teatro estadunidense que exigiam compromisso com as regras do Realismo descritivo. Segundo o argumento dessa parcela da crítica especializada, o lirismo da linguagem e os mecanismos teatrais de expressividade defendidos por Williams obstruem a ação. Por certo, segundo a leitura que aqui se realiza, o argumento não está de 
todo equivocado; a ação obstruída (afastada a negatividade da sentença) torna-se a percepção do indício de que Williams aproxima-se dos protocolos do teatro brechtiano, em especial do Verfremdungseffekt, ou efeito de distanciamento.

Seguiremos os rastros deixados por esta "outra crítica", a que apreende como positivos os deslocamentos da forma, e pelo próprio autor. Interessam-nos "the odd rules of Williams's brand of expressionism" (SHEEHY, 1991, p. 79), assim como as características que Downing Cless (1983, p. 41) localiza ao comparar Camino Real ao teatro épico brechtiano: "the play's structures of alienation and contradiction, its pervasive incongruities, which both frustrate and entice theatre artist". ${ }^{10}$ Nosso intuito é filiar Williams a um Realismo de estrutura ou formal, compreendido como aquele portador de uma forma experimental que, em diversos níveis e em diversas intensidades, deforma o real para acessar seu subterrâneo, suas engrenagens.

Segundo Bentley (1991, p. 310, grifo no original), o caráter ético de Brecht, sua orientação social, faz dele um naturalista. Porém, suas técnicas são antinaturalistas. "Procuram exatamente destruir a ilusão de realidade, que era a intenção primordial do Realismo". Expressionismo e Verfremdungseffekt brechtiano não se vinculam aqui por um acaso. Gerd Bornheim (1992b, p. 112) afirma que Brecht é responsável por "uma progressiva laicização do expressionismo", declaração que destaca uma potencialização política do Expressionismo por meio do que Brecht chama de caráter edificador do teatro, que prima pela manutenção da atenção crítica contra a passividade da audiência. De acordo com Mariângela Lima (2002, p. 221), o moderno teatro épico, entre eles o brechtiano, apesar do compromisso filosófico e histórico e da rejeição do subjetivismo por parte de Brecht, "fez uso frequente das inovações estruturais como a organização em estações, a intercalação de monólogo interior e a flexibilidade espacial e temporal desvendada pela dramaturgia expressionista".

Ubiratan D'Ambrosio (2002, p. 103) aponta a visão subjetiva do mundo, prevalecendo sobre o "real", como princípio fundamental do Expressionismo. Assim, o mundo empírico será representado por meio do filtro repleto de sentimentos latentes, "concedendo aos estados de ânimo um estatuto ontológico privilegiado" (LIMA, 2002, p. 191). Tais características exigem técnicas específicas. Destacamos algumas, presentes em The Mutilated, de Williams, que fazem contrapartida à representação realista-descritiva: a atividade monológica e a prontidão da resposta emocional, os momentos de introspecção, a ênfase expressiva no gesto e na entonação, a retomada do protagonismo, do herói arquetípico e da personagem alegórica.

O ponto fundamental do Verfremdungseffekt é a manutenção da consciência da audiência acerca do caráter de ilusão da representação. $\mathrm{O}$ ator rejeita a transformação total na personagem, mantendo-se como um intermediário entre o texto e a plateia. Preferencialmente, não representa o fato por meio da ação, mas o narra como testemunha do acontecido - Brecht, nesse ponto, substitui o termo "ator" por "demonstrador". A cena deve permitir que surjam no palco elementos técnicos, como as fontes de luz e contrarregras, que introduzem e retiram objetos, antes fora do campo de visão do espectador, o que evidencia a convenção. Só com o alerta que é o Verfremdungseffekt, o "esforço para os incidentes apresentados parecerem estranhos ao público" (BRECHT, 1967b, p.142), a plateia não fica à mercê das eficientes técnicas cenográficas e de atuação e, consequentemente, da empatia, que trabalha no subconsciente e que faz a audiência se identificar tão fortemente com as personagens a ponto de perder seu senso crítico. $\mathrm{O}$ efeito de distanciamento não pretende excluir completamente o pathos, mas direciona as emoções do público a um espaço crítico, no qual não precisam corresponder integralmente às das personagens representadas.

A quarta parede, imaginária e invisível, que separa plateia e cena por meio da moldura geral do consolidado palco à l'italiana e indispensável ao teatro fundado no Realismo descritivo, é outra ilusão que Brecht (1967a, p. 106) combate. O argumento de que o palco é preparado para facilitar a visão da audiência é dissimulação, afirma; seu verdadeiro objetivo é criar a sensação de "espectador impressentido de um acontecimento que está realmente acontecendo". É preciso que o ator dirija-se diretamente à plateia, que, assim, perde sua identificação emotiva com a personagem, desperta da 
hipnose inebriante e nota a falsificação da imagem de realidade própria à representação.

Em “Cena de rua”, Brecht (1967b, p. 148-149) aproxima o Verfremdungseffekt a elementos de interrupção da ação: "O demonstrador deve alternar sua imitação com explicações, o maior número de vezes possível. Os coros e as projeções de documentos do teatro épico e o apelo direto ao público pelos atores estão fundamentados no mesmo princípio". Bentley (1991, p. 309) destaca que o teatro brechtiano traz de volta "os comentários, corais apresentando narradores, canções, solilóquios e outros artifícios 'interruptórios"'. Com a interrupção da ação, dá-se preferência ao fragmentário e ao contraditório, fica denunciado o caráter de artificialidade da representação, e a audiência tem a chance de ativar seu senso crítico.

São, portanto, as afinidades de Tennessee Williams com as propostas de Brecht e do teatro expressionista, anteriormente citadas, produtivas ao Realismo formal, que intentaremos localizar em The Mutilated (1967).

The Mutilated é o drama, em sete cenas, de duas mulheres, Trinket Dugan e Celeste Delacroix Griffin. Se passa no French Quarter, em New Orleans, na véspera e no dia de Natal. Velhas conhecidas, a relação de amizade entre elas está rompida. Trinket, já submetida a uma mastectomia, sente-se acuada e evita Celeste, que usa o segredo da mutilação como forma de submetê-la à chantagem. Celeste é também uma mulher acossada: prostituta, já foi presa por furto e expulsa do Silver Dollar Hotel, um dos espaços do drama, por falta de pagamento; seu irmão, Henry, arruma-lhe emprego em uma padaria, mas não quer que ela use o sobrenome da família e sequer aceita recebê-la em sua casa durante o jantar de Natal. Celeste insiste em passar o Natal bebendo vinho no quarto de Trinket, que, incomodada, tenta desvencilhar-se dela. Um pseudônimo em comum, Agnes Jones, usado no hospital e na delegacia, carrega a dor do passado.

Trinket e Celeste são personagens arquetípicas da literatura dramática de Williams: mulheres solitárias, feridas tão profundamente que atingem o transtorno; que aguardam a chegada de um amor como a solução para o abandono. Encontramos esse modelo, por exemplo, em Bertha, de Hello from Bertha (1946), em Miss Lucretia Collins, de Portrait of a Madonna (1946), em Blanche, de A Streetcar Named Desire (1947). Repetir um modelo é abdicar-se, no que se refere à caracterização das personagens, de representar no palco a "fatia da vida". Dedicar-se com tanta ênfase a um modelo é renunciar a outras personalidades, das quais um drama totalizante, como o pretendido pelo ideal realista-descritivo, não pode abdicar.

Em The Mutilated, a configuração experimental cara ao Realismo formal surge já na descrição da cena. "The set are delicate as Japanese line drawings; they should be so abstract, so spidery, with the exception of Trinket Dugan's bedroom, that the audience will accept the nonrealistic style of the play"11 (WILLIAMS, 2000b, p. 584). Este caráter experimental proposto pelo autor faz com que o espaço das cenas 1, 5, 6 e 7, o Silver Dollar Hotel, surja decomposto, representação da subjetividade das duas perturbadas personagens femininas que habitam o local: Trinket, no único cômodo visível; Celeste, despejada, a vagar pelo saguão enquanto seus objetos ficam trancados no depósito até que pague a conta. Não há parede na fachada do hotel, apenas a moldura da porta principal e o letreiro em néon azul. No saguão, apenas a mesa de Bernie, o recepcionista, um sofá danificado e uma árvore de natal quase sem folhas.

A mais evidente passagem em que a quarta parede, fundamental para a estética realista-descritiva, é questionada em The Mutilated surge na primeira cena. Trinket e Celeste discutem. A prostituta, no corredor do Silver Dollar Hotel, insiste em entrar no quarto da amiga, relembrando bons tempos que passaram juntas. Trinket refuta e explica o motivo, inicialmente para a própria Celeste além da porta. Mas, após quatro frases, Trinket se vira ao público e começa a relatar fatos passados que culminaram no rompimento de sua relação com Celeste:

TRINKET: [...] (She starts addressing the audience instead of Celeste.) I wanted some Moo Goo Gai Pan at the Chinese place on Douphine Street. Oh, no, she said. No. If you want to eat 
boiled rats, do eat Chinese. -I wouldn't dream of it, I told her. [...] (WILLIAMS, 2000b, p. 591) 12 $^{12}$

Para Celeste, do lado de fora do quarto trancado, o discurso de Trinket poderia muito bem estar sendo dirigido a ela; o uso da terceira pessoa seria meramente retórico. Mas Williams (2000b, p. 592, grifo no original) enfatiza a ruptura da quarta parede com o discurso dirigido à audiência quando Celeste interrompe o relato. "Celeste resumes pounding at the stair-landing door"13. Celeste chama a atenção de Trinket, como que exigindo que ela deixe o relato épico do passado e em terceira pessoa, como clama Brecht, e retome a ação, já questionada.

Nas cenas 4 e 5 há uma progressiva transgressão do limite físico que separa palco e plateia. Inicia-se de forma sutil, quando o marinheiro Slim escora-se no arco do proscênio para descansar enquanto as duas personagens femininas discutem. Após Celeste tomar a bolsa de Trinket e sair de cena gritando, Slim escorrega vagarosamente as costas até parar sentado na base do arco. Na cena seguinte, enquanto Trinket tenta persuadir Slim a passar a noite em seu quarto, Celeste aparece por trás do hotel com a bolsa furtada. A prostituta sabe que Trinket está no quarto com Slim e bate o pé na escada que leva ao apartamento na tentativa de chamar a atenção. Celeste joga a bolsa de Trinket no chão e pisa o objeto. Com a aproximação de um policial, vê-se obrigada a desfazer-se dela: resolve chutá-la para o fosso da orquestra. O que parece ser uma tênue extrapolação do palco como espaço da ação torna-se evidente quando Celeste dirige-se ao fosso da orquestra para recuperar a bolsa.

Celeste runs down the stairs. At the bottom, she stops and looks up sobbing at the sky, weeping like a lost child. There is a pause, a silence. Celeste approaches the orchestra pit, stoops, her hand extended. The purse is handed back to her from below. [...] (WILLIAMS, 2000b, p. 613) $)^{14}$

Não só o que está dentro da moldura é parte do espaço da ação, mas a própria moldura, o arco limitador da quarta parede, supostamente invisível, e o fosso da orquestra que separa cena e audiência. A ação extrapola o palco, seu território tradicional, e invade o que o circunscreve. A mão, ou qualquer outro mecanismo, que se estica de dentro do fosso da orquestra para devolver a bolsa a Celeste, logo após a pausa e o silêncio que interrompem a ação, é um elemento técnico exterior à representação cuja aparição no palco realista-descritivo é uma ameaça ao caráter de "realidade" pretendido. A mão que sai do fosso, toda a ação que ultrapassa os limites do palco e também o discurso de Trinket dirigido à audiência e sua interrupção por Celeste, na primeira cena, alcançam o Verfremdungseffekt porque levam à representação da peça de Williams a admissão de sua natureza teatral, conclamando a reflexão do público.

A cena 2 de The Mutilated apresenta uma variedade de elementos relevantes à nossa proposta de leitura. De curta extensão (não preenche três páginas), lembra a cena de um Stationendrama, ou "drama de estação", ${ }^{15}$ forma cara ao Expressionismo e ao teatro épico brechtiano. Deparamo-nos com a ruptura das unidades de ação e espaço. A estrutura esquelética do Silver Dollar Hotel dá lugar a um banco no Jackson Park, onde Trinket se senta. Sozinha no palco, abandona a discussão com Celeste; a tensão criada na primeira cena da peça é suspensa. Se as cenas do Stationendrama são oportunidades para que o herói, que evolui ao longo das estações, encontre-se com outras personagens e contraponha-se a elas, a cena 2 de The Mutilated é a chance de Trinket encontrar-se consigo mesma, levando ao palco outra convenção imprópria ao Realismo descritivo, a atividade monológica. O monólogo aqui é interior. Trinket tenta expulsar de si Agnes Jones, nome que, em seu ânimo, transformou-se na obsessiva vergonha de seu estado:

TRINKET: [...] There's nothing shameful, nothing criminal about an affliction, a -mutilation.... (She shakily lights a cigarette) I am not Agnes Jones, I am Trinket Dugan, and I have absolutely no intention of giving up, not a bit in the world, wouldn't dare to or - care to! - Tonight I'll drive out Agnes Jones, I'll do it right now. How? I'll walk around this bench and when I've walked around it, Agnes Jones will be out of me and never back in! [...] (WILLIAMS, 2000b, p. $599-600)^{16}$

O monólogo é, como afirma Bentley (1991, p. 130), momento para a "emanação do ego individual", contra- 
ponto à representação das relações intersubjetivas e intersociais que compõem a "fatia da vida" pretendida pelo Realismo descritivo. O monólogo evidencia a importância da personagem Trinket para a peça; uma cena é dedicada exclusivamente à exposição de seu interior. "Ao dramaturgo da subjetividade importa em primeiro lugar isolar e intensificar seu personagem central", anota Szondi (2001, p. 59).

Outro importante detalhe na cena 2 é a projeção, sobre um tecido no fundo do palco, da imagem da estátua equestre de Andrew Jackson, sétimo presidente dos Estados Unidos, que empresta seu nome ao parque em que Trinket se encontra. Está aqui, posto em prática, um mecanismo do Plastic Theatre. Nenhuma figura humana além de Trinket ocupa materialmente a cena, o que eleva o apelo emocional (da solidão da protagonista), como defende Williams (2000a, p. 396). Jackson é apenas jogo luminoso, assim como é apenas voz o funcionário do parque que grita dos bastidores: "Gates closing!"17 (WILLIAMS, 2000b, p. 601).

Há, na estética expressionista, a defesa de que alguns sentimentos não podem ser expressos pelo verbo. Reticente, dá espaço ao gestual. Trinket treme ao acender o cigarro, gira em volta do banco; inquieta, levantase subitamente, tonteia, torna a sentar-se. A torrente de desespero e solidão do $e u$ por fim faz materializar um grunhido de difícil descrição:

[...] (She makes a sound like a hooked fish would make if it could make a sound. She rises, then sits back down: she gives way not to despair but to some inner convulsion which makes her produce these dreadful soft cries. They are accompanied by abrupt, indecisive movements to rise or reach out or -Gradually they subside: she pulls herself together.) [...] (WILLIAMS, 2000b, p. 601$)^{18}$

A incapacidade de manifestação do interior da personagem por meio do signo verbal ressurge na cena 6 , materializada no grito, que, de acordo com Bornheim (1992a, p. 66), define a estética expressionista: "gritase porque só resta o grito". A cena 6 é a penúltima da peça. No momento do grito, Trinket vê esfacelar toda sua esperança de que Slim corresponda ao seu desejo.
"She begins to gasp 'Ah,' first very softly, then building to a scream"19 (WILLIAMS, 2000b, p. 615).

Outro elemento interessante à configuração do Realismo formal utilizado em The Mutilated é o coro de carollers, originalmente um grupo que canta canções natalinas. Na peça de Williams, ele surge na abertura da primeira cena, e ao final das cenas 2, 4, 5, 6 e 7. Recurso que remonta às origens do teatro grego, o coro foi refutado pelo Realismo descritivo por não ser um evento verificável no mundo empírico e por seu canto lírico se contrapor às falas cotidianas que devem ser usadas com fidelidade no palco; o prosaico deve excluir todo o poético.

O primeiro detalhe que chama a atenção é o fato de o coro em The Mutilated ser formado por todos seus personagens. Destituídos temporariamente de suas máscaras primeiras, irredutíveis no drama realista-descritivo, juntam-se para formar um novo personagem, que canta e se dispersa como lhe é conveniente. A ação interrompe-se e, sem reserva, um apito aponta o tom no qual os versos serão cantados. $\mathrm{O}$ apito tonal é mais um elemento técnico, normalmente restrito aos ensaios musicais, que é exposto na peça de Williams.

$\mathrm{Na}$ primeira cena, o coro desempenha a função de prólogo. Como acontece em grande parte do texto lírico ao longo da peça, ele antecipa e comenta o que veremos logo a seguir na representação, quebrando parcialmente a tensão. Além disso, os cantos têm caráter interruptório da ação, como sugere Brecht. Conveniente ao período natalino na peça, os versos anunciam desde o início uma redenção, porém passageira, "nearly real”20 (WILLIAMS, 2000b, p. 585), redenção que é, de fato, uma resignação deformada.

Ao final da cena 6, na manhã do dia de Natal, Trinket leva a mão trêmula ao peito. Reclama das dores que volta a sentir, na altura do seio extraído, ao seu diário aberto, imagem da solidão. A noite anterior, que passou com Slim em seu quarto, cheia de expectativa de redenção por meio do amor, foi repleta de maus tratos e insultos; por fim, o marinheiro, bêbado, cai no sono e deixa Trinket mais uma vez sozinha. Celeste, na noite do dia 24, ficou abandonada do lado de fora do Silver Dollar Hotel; sua reação foi a de pegar o terço na bolsa que furtou de Trinket para rezar 
e afirmar repetidas vezes que não é mutilada como a amiga. A solidão das protagonistas é mais intensa que a inicial: as energias empregadas em busca da redenção só abriram mais as feridas. Tudo aponta para uma completa destruição íntima.

É nesse contexto, ao final da cena 6, quando os cantores entram no palco e a ação é interrompida em mais uma oportunidade pelo apito tonal, que surge em cena pela primeira vez, entre os membros do coro, um personagem inusitado, Jack In Black. Sua entrada causa estranheza, inicialmente, por seu figurino sinuoso: veste uma roupa de caubói preta, com brilhantes que imitam diamantes contornando os bolsos da camisa, o cinto, o coldre, e a aba do chapéu. Nenhum dos membros do coro responde ao apito até que Jack In Black surja pela porta do saguão do Silver Dollar Hotel. $\mathrm{O}$ apito é soprado mais três vezes e o coro canta apenas o início da frase: "I think-" (WILLIAMS, 2000b, p. 616). Quando o membro do coro responsável pelo objeto que dá o tom da canção o arremessa ao solo, Jack In Black dá um passo à frente e canta; o restante do coro entoa apenas o refrão. $\mathrm{O}$ texto antecipa a reconciliação entre Trinket e Celeste, que ocorrerá na cena 7. Porém, mais uma vez, fica evidente a transitoriedade do milagre da reconciliação quando Jack In Black adianta na letra da canção que as duas amigas "nearly think it may be true"21 (WILLIAMS, 2000b, p. 616).

O que encontramos na cena 7 é quase uma nova briga entre Trinket e Celeste; enquanto a primeira quer ir à igreja para ouvir os cantos natalinos, a segunda quer por tudo ficar no quarto da amiga, que acabara de aceitar sua reentrada no cômodo. Celeste recomenda que ouçam a canção pelo rádio. Quando Trinket afirma que na catedral Cristo e Nossa Senhora estarão presentes, um marinheiro bêbado, visível apenas ao público, bate à porta. Ela a abre, mas não há mais ninguém. Celeste então sugere que algum espírito entrou no momento em que a amiga abriu a porta $\mathrm{e}$ relembra, epicamente, a oportunidade na qual, quando criança, viu a santa na Sacred Heart Convent School. Por fim, a prostituta afirma que Nossa Senhora está invisível no quarto; a luz transforma-se, como que filtrada por janelas escurecidas, e as duas amigas acabam de joelhos: "a subjective phenomenon of trance falling over the women"22 (WILLIAMS, 2002d, p. 620). Celeste, induzindo Trinket desde o início do "fenômeno", leva a mão da amiga ao suposto manto invisível de Nossa Senhora; as duas o beijam. A dor de Trinket no busto mutilado passa e as duas dizem juntas: "Finally, oh, finally!"23 (WILLIAMS, 2000b, p. 621).

Se a cena 2 de The Mutilated lembra a de um Stationendrama, a última lembra a scène à faire de um melodrama, que ao final da peça soluciona todo impasse, criado ao longo das cenas anteriores e que apontava para um fim trágico. Como que por encantamento, a religiosidade salva as protagonistas do French Quarter, onde o que sempre imperou foi uma fé degradada, como o pinheiro natalino do Silver Dollar Hotel, estabelecimento em que o Natal não é comemorado, como atesta Bernie ao atender a um telefonema, na primeira cena: "No such party here. Nope, no such party"24 (WILLIAMS, 2000b, p. 596).

Porém, a ressalva acerca dessa redenção por meio da religiosidade é a presença simbólica do Destino ou da Morte em Jack In Black, o que sugere que tal desfecho, aparentemente pacífico e abençoado, é apenas uma concessão. O que há, no fim, não é uma redenção, mas a irônica prorrogação do fim desastroso, com o qual é preciso resignar-se; ou a constatação de que o desastre é a própria existência das personagens e seu insistente desejo de mudança.

Jack In Black (sua súbita aparição) é a personificação da denúncia de ilusão - não só do artifício no resgate de Trinket e Celeste por meio de uma religiosidade instantânea, mas da própria pretensão de representação realista-descritiva no teatro. Ao afirmar que manipula as cartas do baralho, os dados e a roleta da vida das protagonistas (WILLIAMS, 2000b, p. 622), o caubói de brilhantes aproxima-se da imagem do dramaturgo, que explicita no texto sua capacidade de arquitetar o drama segundo seus próprios protocolos e de relacioná-lo profundamente com sua subjetividade.

Williams é realista, não na acepção que pretensamente nomeia o operador que reproduz, como na máquina fotográfica, a realidade exterior. $\mathrm{O}$ drama de Tennessee Williams deforma esta imagem. "Nearly real" - o destino de sua representação é como o destino de suas protagonistas em The Mutilated; só assim o dramaturgo 
atinge seu interesse maior, o da abordagem mais próxima, mais íntima da realidade. Os termos de Lescot, ao definir o Realismo formal, podem muito bem ser direcionados a Williams: "impõe à realidade objetiva inúmeras torções, transposições, transformações, isto é, operações prévias a um realismo de estrutura, um realismo no sentido filosófico". Distorcer, por meio da forma experimental, é dar a conhecer, é trazer à superfície uma fração do subterrâneo que nos habita.

\section{Notas}

1. "É axiomático que cada geração compreenda que o seu teatro é, de alguma forma, mais 'real' que o antecessor". Todas as traduções em notas de rodapé são do autor deste artigo.

2. "ambos escrevendo essencialmente segundo o modelo realista".

3. "Não gostei do texto quando o li há algum tempo parcialmente porque pertence ao atual tipo rococódeliquescente de teatro e, principalmente, porque parece estar longe de ser um exemplo brilhante do modelo. O elemento genuíno em Tennessee Williams sempre me pareceu residir em seu realismo: sua habilidade em construir diálogos eloquentes e expressivos a partir do discurso real dos homens e seu dom para o retrato, especialmente o retrato de mulheres infelizes. Há também um elemento espúrio. Às vezes é seu estilo que é espúrio: quando é poético, é frequentemente lascivo e pretensioso".

4. Segundo Heintzelman e Smith-Howard (2005, p. 47-48), Camino Real não alcançou boa recepção. "Audiences were either offended by his political views or bored by what they perceived as a formless play about nothing. Williams cut much of the play's political commentary for the Broadway production; however, he restored it for its first publication in 1953".

5. "O background para Blanche Dubois eram paredes diáfanas e vozes incorpóreas, como as de Joana D’Arc. [...]. A única diferença é que Camino Real nem sequer finge ser realista. $\mathrm{O}$ irreal, que antes nos cercava sutilmente, agora nos encara".

6. "A compaixão de Williams por párias em The Mutilated é, como sempre, sincera; mas a peça em si é construída com excessiva frouxidão para conquistar o envolvimento do público tradicional. Ao mesmo tempo, paradoxalmente, não é suficientemente experimental".

7. O tradutor de Anders, Modesto Carone, explica o neologismo do pesquisador no grifo: é um jogo entre as palavras verrücken (deslocar) e o particípio do verbo, em função adjetiva, verrückt (louco) (Cf. ANDERS, 2007, p. 151).

8. "OExpressionismo etodas as outrastécnicas dramáticas não convencionais têm um único objetivo válido: uma abordagem mais próxima da verdade. Quando uma peça emprega técnicas não convencionais não o faz, ou certamente não deveria fazê-lo, como tentativa de escapar à sua responsabilidade de relacionar-se com a realidade ou como uma fuga da experiência de interpretá-la. É, na verdade, ou deveria ser, a busca por uma abordagem mais próxima, uma expressão mais penetrante e vívida das coisas como elas são".

9. "as estranhas regras do expressionismo de Williams".

10. "as estruturas de alienação e contradição da peça, suas incongruências generalizadas, que simultaneamente frustram e encantam o artista de teatro".

11. "Os cenários são delicados como desenhos japoneses; eles devem ser tão abstratos, tão demasiadamente sutis, com exceção do quarto de Trinket Dugan, que o público aceitará o estilo não realista da peça”.

12. "TRINKET: [...] (Dirige-se inicialmente não a Celeste, mas ao público). Eu queria comer Moo goo gai pan no restaurante chinês na Douphine Street. Ah, não, ela disse. Não. Se você quer comer ratos cozidos, coma comida chinesa. -Eu nunca faria isso, disse a ela. [...]".

13. "Celeste retoma golpeando a porta da escadaria".

14. "Celeste desce correndo as escadas. Embaixo, ela para e olha soluçando ao céu, chorando como uma criança perdida. Há uma pausa, um silêncio. Celeste aproximase do fosso da orquestra; para, com a mão estendida. A bolsa é devolvida a ela de baixo [...]".

15. "No 'drama de estação', o herói, cuja evolução se descreve, é distinguido com máxima clareza das personagens que encontra nas estações de seu caminho. Elas só aparecem na medida em que se encontram com o protagonista, na perspectiva dele e em relação com ele" (SZONDI, 2001, p. 60).

16. “TRINKET: [...] Não há nada de vergonhoso, nada de criminoso no sofrimento, numa - mutilação.... (Trêmula, acende um cigarro) Não sou Agnes Jones, sou Trinket Dugan, e absolutamente não tenho a intenção de desistir, por nada nesse mundo, não ousaria ou - me preocuparia! - Nesta noite vou expulsar Agnes Jones, farei isso agora! Como? Vou caminhar ao redor deste banco e quando terminar Agnes Jones sairá de mim para nunca mais voltar! [...]".

17. "Fechando os portões!".

18. "[...] (Ela emite um som como o que um peixe em um anzol emitiria se pudesse emitir um som. Levantase, volta a se sentar: ela cede não ao desespero, mas a um tipo de convulsão íntima que a faz produzir 
esses terríveis gritos suaves. Eles são acompanhados por movimentos bruscos e indecisos de ascensão ou como se para alcançar algo ou - Gradativamente eles se enfraquecem: ela recupera a calma.) [...]".

19. "Ela começa a arfar 'Ah', a princípio muito suavemente, e depois ascendendo a um grito".

20. "Quase real".

21. "quase acreditam que pode ser verdade".

22. "um fenômeno subjetivo de transe arrebata as mulheres".

23. "Finalmente, oh, finalmente!”.

24. "Sem festa desse tipo por aqui. Não, nada de festa”.

\section{Referências}

ANDERS, Günther. Kafka: pró e contra. Trad. Modesto Carone. São Paulo: Cosac Naify, 2007.

BENTLEY, Eric. The Dramatic Event: an American Chronicle. New York: Horizon, 1954.

O dramaturgo como pensador: um estudo da dramaturgia nos tempos modernos. Trad. Ana Zelma Campos. Rio de Janeiro: Civilização Brasileira, 1991.

BERTHOLD, Margot. História mundial do teatro. Trad. Maria Paula V. Zurawski e J. Guinsburg, Sérgio Coelho e Clóvis Garcia. São Paulo: Perspectiva, 2011.

BORNHEIM, Gerd. Duas características do Expressionismo. In: __ O sentido e a máscara. São Paulo: Perspectiva, 1992a. p. 63-68.

Vigência de Brecht. In: O sentido e a máscara. São Paulo: Perspectiva, 1992b. p. 111-114.

BRECHT, Bertolt. O efeito de distanciamento nos atores chineses. In: Teatro dialético. Trad. Luiz Carlos Maciel e Sérgio Micelli. Rio de Janeiro: Civilização Brasileira, 1967a. p. 104-114.

Cena de rua - Modelo de uma cena de teatro épico. In: Teatro dialético. Trad. Luiz Carlos Maciel e Sérgio Micelli. Rio de Janeiro: Civilização Brasileira, 1967b. p. 141-152.

CLESS, Downing. Alienation and Contradiction in "Camino Real": a Convergence of Williams and Brecht. Theatre Journal, Baltimore, Maryland: The Johns Hopkins University Press, v. 35, n. 1, p. 41-50, mar. 1983.

D’AMBROSIO, Ubiratan. Teoria da relatividade, o princípio da incerteza. In: GUINSBURG, Jacó (Org.). O expressionismo. São Paulo: Perspectiva, 2002. p. $103-$ 120.

FALK, Signi. Tennessee Williams. Trad. Maria Tereza Porciúncula Moraes. Rio de Janeiro: Lidador, 1966.
HEINTZELMAN, Greta; SMITH-HOWARD, Alycia. Critical Companion to Tennessee Williams. New York: Facts on File, 2005.

LESCOT, David. Realismo. In: SARRAZAC, Jean-Pierre (Org.). Léxico do drama moderno e contemporâneo. Trad. André Telles. São Paulo: Cosac Naify, 2012. p. 155-157.

LIMA, Mariângela Alves de. Dramaturgia expressionista. In: GUINSBURG, Jacó (Org.). O expressionismo. São Paulo: Perspectiva, 2002. p. 189-221.

LONDRÉ, Felicia Hardison. Tennessee Williams. New York: Ungar, 1979.

LOSCO, Mireille. Tableau (Quadro). In: SARRAZAC, Jean-Pierre (Org.). Léxico do drama moderno $e$ contemporâneo. Trad. André Telles. São Paulo: Cosac Naify, 2012. p. 176-178.

MAGALDI, Sábato. O texto no teatro. São Paulo: Perspectiva, 2012.

SHEEHY, Catherine. Flexi-Glass: Tennessee Williams's Supremely Malleable Menagerie. Theater, Durham, Carolina do Norte: Duke University Press, v. 22, n. 1, p. 79-82, 1991.

STYAN, John Louis. Modern Drama in Theory and Practice: Realism and Naturalism. Cambridge: Cambridge University Press, 2003.

SZONDI, Peter. Teoria do drama moderno (1880-1950). Trad. Luiz Sérgio Rêpa. São Paulo: Cosac Naify, 2001.

WILLIAMS, Tennessee. The Long Goodbye. In: Twenty-seven Wagons Full of Cotton and Other OneAct Plays. New York: New directions, 1966. p. 157-176.

The Glass Menagerie. In: Plays 19371955. New York: The Library of America, 2000a. p. 394-465.

. The Mutilated. In: Plays 1957-1980. New York: The Library of America, 2000b. p. 583-622.

A Streetcar Named Desire. In: Plays 1937-1955. New York: The Library of America, 2000c. p. 467-564.

Recebido em: 14/07/2016 Aceito em: 07/12/2016 